\title{
Níveis de Substituição do Fosfato Bicálcico pelo Monobicálcico em Dietas para Suínos nas Fases de Crescimento e Terminação 1
}

\author{
Alexandre de Oliveira Teixeira ${ }^{2}$, Darci Clementino Lopes $^{3}$, Paulo Cezar Gomes ${ }^{3}$, João Batista \\ Lopes $^{4}$, Leidimara Feregueti Costa ${ }^{5}$, Vanusa Patrícia de Araújo Ferreira ${ }^{6}$, Sérgio de Miranda Pena ${ }^{7}$, \\ José Aparecido Moreira ${ }^{8}$, Silvano Bünzen ${ }^{7}$
}

\begin{abstract}
RESUMO - Cinqüenta e seis leitões (peso médio inicial de 28,47 kg) foram distribuídos em um delineamento experimental de blocos casualizados, em esquema fatorial 4 x 2 (níveis de substituição do fosfato bicálcico x sexo), com quatro repetições para machos e três para fêmeas e dois animais/baia, para avaliar os efeitos da substituição do fosfato bicálcico pelo fosfato monobicálcico sobre o desempenho e os parâmetros sangüíneos e ósseos de suínos alimentados nas fases de crescimento (30 a $60 \mathrm{~kg}$ de peso) e terminação (60 a 90 kg de peso). As dietas experimentais, à base de milho e farelo de soja e $\mathrm{P}$ suplementado com a substituição de $33,33 \%, 66,67 \%$ e $100 \%$ do fosfato bicálcico (FBC) pelo monobicálcico (MBC), foram formuladas com base nos valores de fósforo total, ou seja, isofosfóricas $(0,56 \%$ e $0,42 \%$ nas fases de crescimento e terminação, respectivamente). Os níveis de substituição do FBC pelo MBC não influenciaram o desempenho, os pesos absoluto e relativo dos rins e do fígado, o rendimento de carcaça e os parâmetros sangüíneos dos suínos. Entretanto, observou-se diminuição linear nos teores de cinza, de fósforo e de cálcio dos ossos e aumento linear na espessura da camada compacta e na relação camada compacta/periósteo dos ossos com a substituição do FBC pelo MBC. A substituição total e/ou parcial do fosfato bicálcico pelo monobicálcico não influenciou o desempenho dos suínos nas fases de crescimento e terminação.
\end{abstract}

Palavras-chave: flúor, histologia osso, nutrição, resistência, soro sangüíneo

\section{Levels of Substitution of Phosphate Dicalcium by Monodicalcium in the Diets of Swine in the Growing and Finishing Phases}

\begin{abstract}
Fifty-six pigs (average initial weight of $28.47 \mathrm{~kg}$ ) were assigned to a randomized blocks design, in a factorial scheme $4 \times 2$ (levels of dicalcium phosphate substitution $\mathrm{x}$ sex) with four repplicates for males and three for females, with two animals per experimental unit, to evaluate the effects of replacement levels of phosphate dicalcium by phosphate monodicalcium on the performance, blood and bone parameters of swine fed during the growing (30 to $60 \mathrm{~kg}$ ) and finishing (60 to $90 \mathrm{~kg}$ ) phases. Corn and soybean meal based -diets with phosphorus supplemented with replacement levels of 33.33, 66.67 and 100\% of phosphate dicalcium (FBC) by monodicalcium (MBC) were formulated based on the values of total phosphorus, i.e., isophosphoric $(0.56$ and $0.42 \%$ in the growth and finishing phases, respectively). The levels of substitution of FBC for MBC did not influence the performance, absolute and relative weight of the kidneys and liver, carcass yield and blood parameters. However, a linear decrease was observed in the ash, phosphorus and calcium contents of the bones and a lineal increase in the thickness of the compact layer and in the layer compact/periosteal relationship of the bones with the substitution of FBC by MBC. It was conclude that during the growth and finishing phases the total and/or partial substitution of phosphate dicalcium by monodicalcium does not influence the performance of the animals.
\end{abstract}

Key Words: fluorine, histology bone, nutrition, breaking strength, blood serum

\section{Introdução}

A baixa disponibilidade de fósforo nos alimentos vegetais usados nas rações de suínos torna necessária a suplementação deste mineral a partir de fontes como o fosfato bicálcico, o que onera o custo de produção, uma vez que o fósforo inorgânico é, entre os elementos minerais, o mais caro (Nunes etal., 2001). Segundo Viana (1985), na escolha de uma fonte suplementar de fósforo, devem-se considerar o custo por unidade do elemento, a forma química em que o elemento está presente, a granulometria, a solubilidade e o teor de impurezas.

\footnotetext{
${ }^{1}$ Projeto parcialmente financiado pela BUNGE FERTILIZANTES S/A.

2 Zootecnista e doutor em Zootecnia - UFV - 36.571-000 - Viçosa - MG (alexandre.teixeira@bunge.com).

3 Professores do Departamento de Zootecnia - UFV - 36.571-000 - Viçosa - MG.

4 Professor do Departamento de Zootecnia - UFPI - Teresina - PI.

5 Zootecnista, Mestre em Zootecnia - UFV - 36571-000 - Viçosa - MG.

6 Zootecnista e professora titular da FEAD - Belo Horizonte - MG.

7 Zootecnista - UFV - 36.571-000 - Viçosa - MG.

8 Pesquisador CENA/USP - Piracicaba - SP.
} 
O fosfato bicálcico (FBC) - um suplemento de fósforo para animais amplamente empregado nas rações - é resultante da acidificação do concentrado apatítico, proveniente da flotação da rocha finamente moída, normalmente, com ácido sulfúrico, resultando em ácido fosfórico, que é desfluorizado e desulfatado. A reação entre o rejeito carbonatítico e o ácido fosfórico resulta no FBC, produto com baixos níveis de flúor e de outros contaminantes (Lima et al., 1995). Possui, no mínimo, $18 \%$ de fósforo, relação mínima fósforo/flúor de 100/1 e máxima de cálcio/ fósforo de 1,38/1.

Nos últimos anos, pesquisas têm sido feitas, no sentido de avaliar fontes alternativas ao fosfato bicálcico na alimentação animal, buscando-se reduzir o custo de produção, sem prejudicar o desempenho produtivo. No entanto, a maioria das pesquisas foi realizada a partir da avaliação da substituição do FBC pelos fosfatos de rocha (Cardoso, 1991; Veloso, 1991), que, todavia, sofrem restrições de uso na alimentação animal, em razão dos baixos teores de fósforo (P), reduzidos valores de biodisponibilidade de fósforo e elevados teores de flúor. Os fosfatos monoamônico e monocálcico, por outro lado, constituem-se em boas fontes de fósforo para suínos (Barbosa et al., 1992).

No mercado internacional, estão disponíveis vários produtos de composição e valor biológico variáveis - fosfato diamônio, fosfato de sódio monobásico, tripolifosfato de sódio e ácido fosfórico-, que, porém, são menos usados, por sua instabilidade química, pelo custo mais elevado ou, ainda, pelos cuidados especiais no manuseio (ANDIF, 1997).

A utilização de fosfato monobicálcico no Brasilé recente e o número de pesquisas utilizando esta fonte é incipiente. $\mathrm{O}$ fosfato monobicálcico é resultante da reação do ácido fosfórico com o concentrado apatítico, em condições que favorecem a evaporação do flúor. É um produto que se caracteriza pela maior presença de fosfato monocálcico, cuja característica é a alta solubilidade em água. Possui, no mínimo, 20\% de fósforo, relação mínima fósforo/flúor de 60/1 e máxima de cálcio/fósforo de 1,15/1. Portanto, podese tornar uma fonte viável para alimentação de monogástricos com a finalidade de balancear os níveis de cálcio e de fósforo das rações.

Muitos critérios têm sido usados para avaliar a utilização de fósforo nos ingredientes da ração de suínos: desempenho, resistência óssea, cinza no osso, fósforo e fosfatase alcalina no soro, anormalidades no esqueleto, distribuição do fósforo nos tecidos, taxa de incorporaçãoe biodisponibilidade do fósforo(Ammerman et al., 1963; Peeler, 1972; Gomes, 1988; Lopes, 1998; Lopes et al., 1999; Figueirêdo et al., 2001).

Os ossos podem ser avaliados, também, pela técnica de histomorfometria, com o objetivo de quantificar estruturas do tecido ósseo, como a espessura do periósteo e da camada compacta, diminuindo, assim, a subjetividade dos achados histológicos (Mores et al., 1999).

Neste estudo, foram avaliados os efeitos da substituição do fosfato bicálcico pelo fosfato monobicálcico sobre o desempenho e os parâmetros sangüíneos e ósseos de suínos.

\section{Material e Métodos}

O experimento foi conduzido no Setor de Suinocultura do Departamento de Zootecnia (DZO) da Universidade Federal de Viçosa (UFV), em Viçosa, Minas Gerais, no período de novembro de 2001 a maio de 2002.

Foram utilizados 56 leitões, com peso médio inicial de $28,47 \mathrm{~kg}$, distribuídos em 28 baias, em delineamento experimental de blocos casualizados, em esquema fatorial $4 \times 2$ (níveis de substituição do fosfato bicálcico $\mathrm{x}$ sexo), com quatro repetições para machos e três para fêmeas e dois animais/unidade experimental. Os animais foram alojados em baias de crescimento e terminação, utilizando-se equipamentos, manejo e programa profilático semelhantes aos empregados nas explorações comerciais de suínos. A distribuição dos animais ocorreu conforme o sexo, peso e parentesco.

As rações das fases de crescimento $(30$ a $60 \mathrm{~kg}$ ) e de terminação (60 a $90 \mathrm{~kg}$ ) foram formuladas para atender às exigências dos animais, conforme recomendações de Rostagno et al. (2000). As análises bromatológicas dos ingredientes e das dietas foram realizadas no Laboratório de Nutrição Animal do Departamento de Zootecnia da Universidade Federal de Viçosa, segundo metodologia descrita por Silva (1990).

As rações-controle, à base de milho moído e farelo de soja, foram isoprotéicas, contendo 17,9 e $16,8 \%$ de PB para as fases de crescimento e terminação, respectivamente, e isocalóricas, com $3.400 \mathrm{kcal} / \mathrm{kg}$ de ED.

Foram adotados os seguintes tratamentos: $100 \% \mathrm{FBC}=$ dieta basal com $100 \%$ do fosfato suplementado com fosfato bicálcico; 33\% MBC =

R. Bras. Zootec., v.34, n.1, p.142-150, 2005 
dieta basal com $66,67 \%$ do fosfato suplementado com FBC e $33,33 \%$ do fosfato monobicálcico (MBC); $66 \% \mathrm{MBC}=$ dieta basal com $33,33 \%$ do fosfato suplementado com FBC e 66,67\% do MBC; e $100 \%$ $\mathrm{MBC}=$ dieta basal com $100 \%$ do fosfato suplementado com MBC.

As dietas experimentais, formuladas com base nos valores de fósforo total, foram isofosfóricas, com 0,56 e $0,42 \%$ nas fases de crescimento e terminação, respectivamente (Tabela 1).
No final das fases de crescimento $(59,90 \mathrm{~kg}$ de peso) e terminação (95,34 kg de peso), foram efetuadas pesagens dos animais e das sobras de ração e coletadas amostras de sangue, por punção na região dos sinos orbitais, em todos os animais do bloco, para determinação de fosfatase alcalina, de fósforo e de cálcio. Os teores de fosfatase alcalina, de fósforo e de cálcio foram analisados no Laboratório de Bioquímica da Universidade Federal de Viçosa, utilizando kits comerciais.

Tabela 1 - Composição das rações experimentais nas fases de crescimento e terminação Table 1 - Composition of experimental diets in the growing and finishing phases

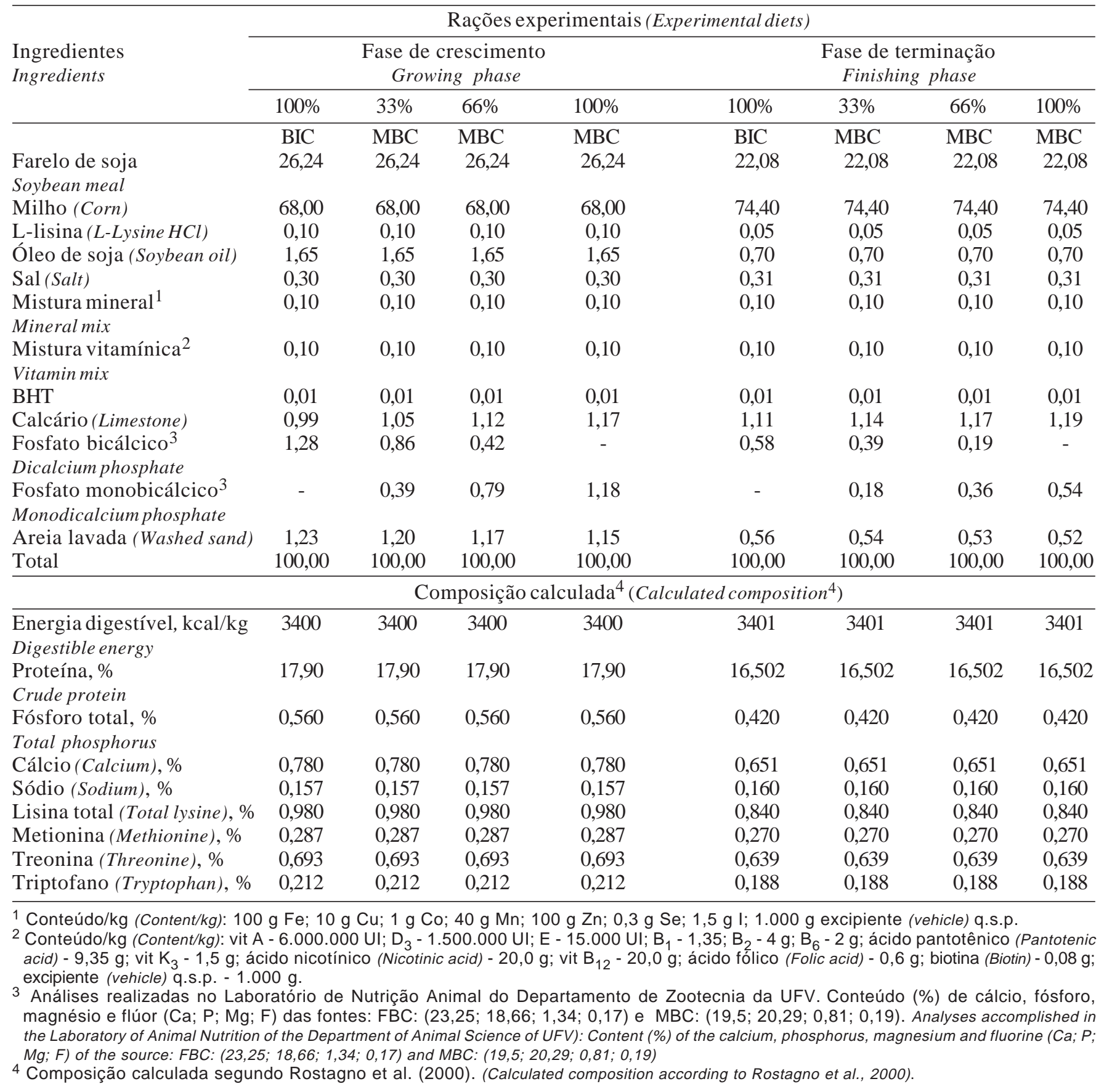

R. Bras. Zootec., v.34, n.1, p.142-150, 2005 
No final de cada bloco experimental, após jejum de 24 horas, foi abatido um animal por baia, com o peso próximo da média do bloco. Foi coletada a pata anterior direita e fragmentos com, aproximadamente, $1 \mathrm{~cm}$ de comprimento, da sexta costela a cerca de 10 $\mathrm{cm}$ abaixo da articulação costoventral, para análise histológica. Em seguida, efetuou-se a pesagem de fígado, rins e carcaça.

As patas coletadas foram colocadas em panela de alumínio, envoltas em papel-alumínio, e fervidas, para amolecer a pele e a carne que envolve os ossos. Após descarnamento, foram lavadas em água fria e, com auxílio de escova, retirados os resíduos de carne e a cartilagem proximal. Mediram-se o comprimento e o diâmetro dos ossos, com paquímetro, que, em seguida, foram pesados.

O terceiro metacarpiano do membro anterior de um animal por baia foi submetido à resistência a quebra ou flexão, utilizando o aparelho Instron Corporation IX Automated Materials Testing System - modelo 4204, pertencente ao Laboratório de Papel e Celulose do Departamento de Engenharia Florestal da Universidade Federal de Viçosa.

Após quebra, os ossos foram desengordurados em extrator Soxhlet e levados à estufa ventilada a $55^{\circ} \mathrm{C}$, por de 72 horas; em seguida, foram triturados em moinho de bola, para se proceder à secagem definitiva em estufa a $105^{\circ} \mathrm{C}$, por 24 horas. A determinação dos teores de cinzas foi feita em forno mufla a $600^{\circ} \mathrm{C}$; as concentrações de cálcio e de magnésio dos ossos, por espectrofotometria de absorção atômica; e de fósforo, por colorimetria, de acordo com a metodologia descrita por Silva (1990). As análises de flúor foram realizadas no laboratório da Rodes Química Cajati LTDA, em Cajati - São Paulo.

Os fragmentos de costela foram lavados imediatamente em solução fisiológica, fixados em BOUIN por 24 horas, desidratados em álcool etílico, diafanizados em xilol e incluídos em parafina. Com micrótomo, realizaram-se secções com $7 \mathrm{~mm}$ de espessura, sendo os cortes corados em hematoxilina e eosina. As análises morfométricas foram feitas por intermédio de microscópio, com aumento de 40 vezes, acoplado ao analisador de imagem "Image-Pro Plus 1.3.2" (1994).

Para estudo histológico do osso da costela, foram feitas 140 medidas por tratamento em 20 pontos distintos da superfície do osso cortical, para determinar a espessura do periósteo, que compreende desde a superfície em contato com o tecido muscular até a superfície da camada compacta, e a largura da camada compacta, que compreende desde a superfície periostal até o osso trabecular.

A análise estatística dos parâmetros estudados no experimento foi realizada de acordo com o programa Statistical Analysis System (SAS, 1996), sendo os dados submetidos à análise de regressão.

\section{Resultados e Discussão}

Os dados de ganho de peso médio diário (GP), de consumo de ração médio diário $(\mathrm{CR})$ e de conversão alimentar (CA) de suínos alimentados com ração contendo níveis de substituição do fosfato bicálcico pelo monobicálcico, nas fases de crescimento e terminação e de acordo com o sexo, são apresentados na Tabela 2.

Não houve interação $(P>0,05)$ entre os níveis de substituição e sexo dos animais. Os machos tiveram maior $(\mathrm{P}<0,05)$ GP e CR que as fêmeas e a pior $(\mathrm{P}<0,05)$ conversão alimentar, em todos os períodos.

A substituição do FBC pelo MBC não influenciou $(\mathrm{P}>0,05)$ o GP, $\mathrm{CR}$ e CA dos animais em todos os períodos. Apesar de não ter sido diferente nos animais que consumiram ração com níveis crescentes de MBC, o GP apresentou tendência de aumento em relação àqueles dos tratamentos com $\mathrm{FBC}$.

As fontes de fósforo à base de fosfato e monocálcico podem substituir o fosfato bicálcico em rações de suínos do sétimo dia até a fase de acabamento, sem prejudicar o desempenho dos animais (Barbosa et al., 1995; Barbosa et al., 1992; Medeiros, 1999). Segundo Gomes (1995), os fosfatos de Tapira, monocálcico, Fosforindus, monoamônio e as diversas combinações destes elementos constituem fontes de fósforo que podem ser utilizadas em rações de suínos nas fases de crescimento e terminação.

O mesmo comportamento pode ser observado neste experimento, em que a utilização de fosfato monobicálcico promove resultados de desempenho semelhantes aos do FBC e, ainda, possui baixa contaminação por metais pesados e flúor e maior biodisponibilidade do fósforo que os fosfatos de rochas usados em outros experimentos.

Economicamente, a substituição do fosfato bicálcico pelo monobicálcico será viável quando o preço do monobicálcico for, no máximo, $10 \%$ superior ao fosfato bicálcico, pois o MBC possui aproximadamente $10 \%$ mais fósforo que o $\mathrm{FBC}$.

Os dados de pesos absoluto e relativo do fígado e rim e o rendimento de carcaça de suínos alimentados

R. Bras. Zootec., v.34, n.1, p.142-150, 2005 
Tabela 2 - Ganho de peso diário (GP), consumo ração médio diário (CR) e conversão alimentar de suínos alimentados com ração contendo níveis crescentes de substituição do fosfato bicálcico pelo monobicálcico nas fases de crescimento e terminação, de acordo com o sexo ( $M$ = macho; $F$ = fêmea e $C$ = média)

Table 2 - Weight gain daily (DWG), feed intake daily (DFI) and feed / gain ratio(F/G) of swine fed with ration contend increasing levels of substitution of the phosphate dicalcium for the mono-dicalcium in the growing and finishing phase, according to $\operatorname{sex}(M=$ male; $F=$ female and $X=$ mean $)$

\begin{tabular}{|c|c|c|c|c|c|c|}
\hline \multirow{2}{*}{$\begin{array}{l}\text { Parâmetros } \\
\text { Parameters }\end{array}$} & \multirow{2}{*}{$\begin{array}{l}\text { Sexo } \\
\text { Sex }\end{array}$} & \multicolumn{4}{|c|}{ Níveis de substituição (Substitution Levels) } & \multirow{2}{*}{$\begin{array}{l}\mathrm{CV}^{1} \\
(\%)\end{array}$} \\
\hline & & $100 \% \mathrm{FBC}$ & $33 \% \mathrm{MBC}$ & $66 \% \mathrm{MBC}$ & $100 \% \mathrm{MBC}$ & \\
\hline GP - 30 a $60 \mathrm{~kg}$ & $\operatorname{Macho}(M)$ & 0,895 & 0,909 & 0,938 & 0,928 & \\
\hline \multirow[t]{2}{*}{$D W G-30$ to $60 \mathrm{~kg}$} & Fêmea $(F)$ & 0,703 & 0,823 & 0,739 & 0,793 & \\
\hline & Médias $(X)$ & 0,799 & 0,866 & 0,839 & 0,860 & 11,39 \\
\hline GP - 60 a $90 \mathrm{~kg}$ & $\operatorname{Macho}(M)$ & 1,044 & 0,965 & 1,071 & 1,046 & \\
\hline \multirow[t]{2}{*}{$D W G-60$ to $90 \mathrm{~kg}$} & Fêmea $(F)$ & 0,925 & 0,831 & 0,831 & 0,987 & \\
\hline & Médias $(X)$ & 0,985 & 0,898 & 0,951 & 1,016 & 9,95 \\
\hline GP - 30 a $90 \mathrm{~kg}$ & $\operatorname{Macho}(M)$ & 0,968 & 0,936 & 1,004 & 0,986 & \\
\hline \multirow{2}{*}{$D W G-30$ to $90 \mathrm{~kg}$} & Fêmea $(F)$ & 0,812 & 0,827 & 0,784 & 0,894 & \\
\hline & Médias $(X)$ & 0,890 & 0,881 & 0,894 & 0,940 & 9,40 \\
\hline CR - 30 a $60 \mathrm{~kg}$ & $\operatorname{Macho}(M)$ & 2,117 & 2,203 & 2,277 & 2,145 & \\
\hline \multirow[t]{2}{*}{$D F I-30$ to $60 \mathrm{~kg}$} & Fêmea $(F)$ & 1,721 & 1,929 & 1,790 & 1,767 & \\
\hline & Médias $(X)$ & 1,919 & 2,066 & 2,034 & 1,956 & 8,69 \\
\hline CR - 60 a $90 \mathrm{~kg}$ & $\operatorname{Macho}(M)$ & 3,118 & 3,026 & 3,076 & 3,161 & \\
\hline \multirow[t]{2}{*}{ DFI - 60 to $90 \mathrm{~kg}$} & Fêmea $(F)$ & 2,321 & 2,283 & 1,978 & 2,254 & \\
\hline & Médias $(X)$ & 2,720 & 2,654 & 2,527 & 2,707 & 11,80 \\
\hline CR - 30 a $90 \mathrm{~kg}$ & $\operatorname{Macho}(M)$ & 2,617 & 2,615 & 2,676 & 2,653 & \\
\hline \multirow{2}{*}{$D F I-30$ to $90 \mathrm{~kg}$} & Fêmea $(F)$ & 2,021 & 2,106 & 1,884 & 2,011 & \\
\hline & Médias $(X)$ & 2,319 & 2,360 & 2,280 & 2,332 & 9,65 \\
\hline CA - 30 a $60 \mathrm{~kg}$ & $\operatorname{Macho}(M)$ & 2,37 & 2,42 & 2,43 & 2,31 & \\
\hline \multirow[t]{2}{*}{$F / G-30$ to $60 \mathrm{~kg}$} & Fêmea $(F)$ & 2,45 & 2,34 & 2,42 & 2,23 & \\
\hline & Médias $(X)$ & 2,40 & 2,39 & 2,42 & 2,27 & 8,04 \\
\hline CA - 60 a $90 \mathrm{~kg}$ & $\operatorname{Macho}(M)$ & 2,99 & 3,14 & 2,87 & 3,02 & \\
\hline \multirow[t]{2}{*}{$\mathrm{F} / \mathrm{G}-60$ to $90 \mathrm{~kg}$} & Fêmea $(F)$ & 2,51 & 2,75 & 2,38 & 2,28 & \\
\hline & Médias $(X)$ & 2,76 & 2,96 & 2,66 & 2,66 & 10,32 \\
\hline $\mathrm{CA}-30$ a $90 \mathrm{~kg}$ & $\operatorname{Macho}(M)$ & 2,70 & 2,79 & 2,67 & 2,69 & \\
\hline \multirow{2}{*}{$\mathrm{F} / \mathrm{G}-30$ to $90 \mathrm{~kg}$} & Fêmea $(F)$ & 2,49 & 2,55 & 2,40 & 2,25 & \\
\hline & Médias $(X)$ & 2,61 & 2,68 & 2,55 & 2,48 & 5,88 \\
\hline
\end{tabular}

1 Coeficiente de variação (coefficient of variation).

2 FBC: fosfato bicálcico (FBC: Dicalcium phosphate); MBC: Fosfato monobicálcico (MBC: Monodicalcium phosphate).

com ração contendo níveis de substituição do fosfato bicálcico pelo monobicálcico, nas fases de crescimento e terminação, são apresentados na Tabela 3.

Não houve interação $(P>0,05)$ entre os níveis de substituição e sexo. Não foram observadas também diferenças $(\mathrm{P}>0,05)$ entre machos e fêmeas em todos os parâmetros estudados, exceto para peso absoluto do fígado, que foi maior $(\mathrm{P}<0,05)$ nos machos.

$\mathrm{O}$ aumento da substituição do $\mathrm{FBC}$ pelo $\mathrm{MBC}$ nas dietas experimentais não influenciou $(\mathrm{P}>0,05)$ os pesos absoluto e relativo dos órgãos e o rendimento de carcaça de suínos aos $90 \mathrm{~kg}$ de peso.

Os teores de cálcio (Ca), de fósforo $(\mathrm{P})$ e de fosfatase alcalina (FA) do soro sangüíneo de suínos aos 60 e aos $90 \mathrm{~kg}$ de peso, em função das dietas experimentais, são apresentados na Tabela 4.
Não houve interação $(P>0,05)$ entre os níveis de substituição e sexo. Também não foram observadas diferenças $(\mathrm{P}>0,05)$ entre machos e fêmeas em todos os parâmetros estudados, exceto para atividade da fosfatase alcalina aos $60 \mathrm{~kg}$ de peso, que foi maior $(\mathrm{P}<0,05)$ nas fêmeas.

A substituição do FBC pelo MBC não influenciou ( $\mathrm{P}>0,05)$ os parâmetros sangüíneos; entretanto, a fosfatase alcalina dos animais que consumiram dieta FBC apresentaram tendência de redução da atividade, à medida que o $\mathrm{FBC}$ foi substituído pelo $\mathrm{MBC}$.

A fosfatase alcalina é uma enzima que catalisa a hidrólise de ésteres de fosfato, com vida média no sangue de 24 a 48 horas. Sua concentração sérica tem sido amplamente utilizada como marcador da remodelagem óssea; em humanos, é um marcador 
Tabela 3- Pesos absolutos ( $\mathrm{g}$ ) e relativos (\% da carcaça) de fígado e rins e rendimento de carcaça de suínos alimentados com ração contendo níveis crescentes de substituição do fosfato bicálcico pelo monobicálcico, nas fases de crescimento e terminação

Table 3 - Absolute $(\mathrm{g})$ and relative (\% of carcass) weights liver of and kidney, and carcass yield (\%) of swines fed ration with increasing levels of substitution of the phosphate dicalcium by monodicalcium in the growing and finishing phases

\begin{tabular}{|c|c|c|c|c|c|}
\hline \multirow[t]{2}{*}{$\begin{array}{l}\text { Parâmetros } \\
\text { Parameters }\end{array}$} & \multicolumn{4}{|c|}{$\begin{array}{c}\text { Níveis de substituição } \\
\text { Substitution levels }\end{array}$} & \multirow[b]{2}{*}{$\mathrm{CV}^{1}(\%)$} \\
\hline & $100 \% \mathrm{FBC}$ & $33 \% \mathrm{MBC}$ & $66 \% \mathrm{MBC}$ & $100 \% \mathrm{MBC}$ & \\
\hline Fígado (kg) (Liver) & 1,68 & 1,68 & 1,73 & 1,80 & 16,92 \\
\hline $\operatorname{Rim}(\mathrm{kg})$ (Kidney) & 0,313 & 0,327 & 0,322 & 0,348 & 10,33 \\
\hline Relativo fígado (\%) (Relative liver) & 1,87 & 1,85 & 1,81 & 1,89 & 17,37 \\
\hline Relativo rim (\%) (Relative kidneys) & 0,347 & 0,359 & 0,339 & 0,364 & 12,02 \\
\hline Rendimento carcaça (\%) (Carcass yield) & 77,21 & 78,22 & 76,39 & 77,77 & 4,45 \\
\hline
\end{tabular}

1 Coeficiente de variação (coefficient of variation).

2 FBC: fosfato bicálcico (FBC: Dicalcium phosphate); MBC: Fosfato monobicálcico (MBC. Monodicalcium phosphate).

Tabela 4- Efeito de níveis crescentes de substituição do fosfato bicálcico pelo monobicálcico sobre o teor de fosfatase alcalina (FA), fósforo (P) e cálcio (Ca) do soro sangüíneo de suínos aos 60 e $90 \mathrm{~kg}$ de peso

Table 4 - Effect of increasing substitution levels of phosphate by monodicalcium into the content of alkaline phosphatase (PA), phosphorus $(P)$ and calcium (Ca), of the blood serum swine to the 60 and $90 \mathrm{~kg}$ of weight

\begin{tabular}{|c|c|c|c|c|c|}
\hline \multirow[t]{2}{*}{$\begin{array}{l}\text { Parâmetros } \\
\text { Parameters }\end{array}$} & \multicolumn{4}{|c|}{$\begin{array}{l}\text { Níveis de substituição } \\
\text { Substitution levels }\end{array}$} & \multirow[b]{2}{*}{$\mathrm{CV}^{1}(\%)$} \\
\hline & $100 \% \mathrm{FBC}$ & $33 \% \mathrm{MBC}$ & $66 \% \mathrm{MBC}$ & $100 \% \mathrm{MBC}$ & \\
\hline FA - $60 \mathrm{~kg}(\mathrm{UI})$ & 442,93 & 404,43 & 426,43 & 409,43 & 11,91 \\
\hline FA - $90 \mathrm{~kg}(\mathrm{UI})$ & 439,07 & 374,50 & 405,36 & 404,69 & 11,98 \\
\hline $\mathrm{P}-60 \mathrm{~kg}(\mathrm{mg} / \mathrm{dL})$ & 9,35 & 8,95 & 9,37 & 8,81 & 8,08 \\
\hline $\mathrm{P}-90 \mathrm{~kg}(\mathrm{mg} / \mathrm{dL})$ & 8,39 & 8,45 & 8,75 & 8,74 & 8,99 \\
\hline $\mathrm{Ca}-60 \mathrm{~kg}(\mathrm{mg} / \mathrm{dL})$ & 12,94 & 12,50 & 13,24 & 12,89 & 5,66 \\
\hline $\mathrm{Ca}-90 \mathrm{~kg}(\mathrm{mg} / \mathrm{dL})$ & 13,82 & 13,95 & 13,75 & 13,40 & 4,25 \\
\hline
\end{tabular}

1 Coeficiente de variação (coefficient of variation).

2 FBC: Fosfato bicálcico (FBC: Dicalcium phosphate) MBC: Fosfato monobicálcico (MBC: Monodicalcium phosphate).

útil. Embora a medida de sua atividade envolva grande variedade de isoenzimas que se originam dos intestinos, rins, pâncreas, placenta, fígado e osso, as duas maiores fontes desta enzima são o osso (osteoblasto) e o fígado (células endoteliais).

A fosfatase alcalina osso-específica está localizada na membrana plasmática do osteoblasto, sendo liberada na circulação como um dímero. O seu papel exato é desconhecido, mas, in vivo, está envolvida na formação e mineralização óssea e correlaciona-se com a fosfatase alcalina total e osteocalcina; sua vantagem é ser relativamente independente de doenças que afetam outras fontes de fosfatase alcalina (Åkesson, 1995, citado por Penido et al., 2003).

A dosagem da fosfatase alcalina em suínos é discutida. Boyd et al. (1983) verificaram que a disponibilidade de fósforo no milho com alta umidade foi semelhante quando determinada com base na resistência à quebra de osso ou na atividade de fosfatase alcalina como critério de resposta. Por outro lado, Doige et al. (1975) observaram que os níveis de fosfatase alcalina no soro apresentam pouco valor no diagnóstico de deficiência de cálcio ou fósforo.

Koch \& Mahan (1986) e Engstron et al. (1985) encontraram efeito linear significativo na concentração de fósforo inorgânico no soro sangüíneo de suínos em terminação recebendo níveis crescentes de fósforo dietético. Diferentemente dos resultados desta pesquisa, esses autores verificaram que a hipofosfatemia se instalou progressivamente nos leitões alimentados com as rações deficientes em fósforo, atingindo média mínima de fósforo, no plasma, em torno de 34 a 41 dias de restrição do mineral na ração, em conseqüência da depressão das reservas lábeis do elemento nos tecidos de reserva de fósforo no animal. 
Os resultados de comprimento, peso, diâmetro, resistência, teores de gordura, cinza, cálcio, fósforo, magnésio e flúor do osso do terceiro metacárpio, espessura do periósteo e da camada compacta e relação camada compacta/periósteo do osso da costela dos suínos alimentados com ração contendo níveis de substituição do fosfato bicálcico pelo monobicálcico, nas fases de crescimento e terminação, encontram-se na Tabela 5.

Não houve interação $(P>0,05)$ entre os níveis de substituição e sexo. Não foram observadas também diferenças $(\mathrm{P}>0,05)$ entre os sexos, para todos os parâmetros estudados.

As dietas experimentais não influenciaram ( $\mathrm{P}>0,01)$ comprimento, peso, diâmetro, resistência, teores de gordura, magnésio e flúor do osso terceiro metacárpio, bem como a espessura do periósteo da costela dos suínos.

A substituição do $\mathrm{FBC}$ pelo $\mathrm{MBC}$ provocou redução linear no teor de cinza na ASA $(\mathrm{P}<0,05$; $\left.\mathrm{Y}=52,2365-0,02984 \mathrm{x} ; \mathrm{R}^{2}=98 \%\right)$, cinza na ASE $\left(\mathrm{P}<0,05 ; \mathrm{Y}=54,8264-0,03859 \mathrm{x} ; \mathrm{R}^{2}=100 \%\right)$, fósforo
$\left(\mathrm{P}<0,05 ; \mathrm{Y}=11,7399-0,00701 \mathrm{x} ; \mathrm{R}^{2}=98 \%\right)$ e cálcio $\left(\mathrm{P}<0,05 ; \mathrm{Y}=19,3922-0,0149 \mathrm{x} ; \mathrm{R}^{2}=88 \%\right)$ no osso dos animais que consumiram níveis crescentes de MBC. No entanto, a substituição do FBC pelo MBC provocou aumento linear na camada compacta $\left(\mathrm{P}<0,01 ; \mathrm{Y}=513,483+220,493 \mathrm{x} ; \mathrm{R}^{2}=77 \%\right)$ e na relação periósteo/camada compacta $(\mathrm{P}<0,01$; $\left.\mathrm{Y}=4,0634+2,4150 \mathrm{x} ; \mathrm{R}^{2}=66 \%\right)$.

O cálcio de origem vegetal encontra-se, em grande parte, sob a forma de fitato ou oxalato, tornando-se pouco solúvel e pouco absorvível (Gueguen, 1990). A suplementação de cálcio é feita com calcário calcítico. Entretanto, a maioria dos suplementos de fósforo também possui elevados e variados teores de cálcio. Segundo Ross et al. (1984), o cálcio contido nos diversos suplementos minerais é completo e igualmente assimilável. Entretanto, encontra-se pouca informação quanto à biodisponibilidade de cálcio dos diferentes suplementos de fósforo contendo cálcio (Cromwell, 1989). A partir dos resultados obtidos neste experimento, fica clara a necessidade de se conhecer não apenas a biodisponibilidade de fósforo das fontes de

Tabela 5 - Comprimento, peso, diâmetro, resistência, teor de gordura, cinza, cálcio, fósforo, magnésio e flúor, espessura do periósteo e da camada compacta e a relação camada compacta/periósteo do osso de suínos alimentados com ração contendo níveis de substituição do fosfato bicálcico pelo monobicálcico, nas fases de crescimento e terminação

Table 5 - Length, weigh, diameter, breaking strength, content of the fat, ash, calcium, phosphorus, magnesium and fluorine and periosteal thickness, and compact layer and relationship compact layer/thickness periosteal of the bone of swine fed with diet contend increasing levels of substitution phosphate dicalcium by monodicalcium in the growing and finishing phase

\begin{tabular}{|c|c|c|c|c|c|}
\hline \multirow[t]{2}{*}{$\begin{array}{l}\text { Parâmetros } \\
\text { Parameters }\end{array}$} & \multicolumn{4}{|c|}{$\begin{array}{l}\text { Níveis de substituição } \\
\text { Substitution levels }\end{array}$} & \multirow[b]{2}{*}{$\mathrm{CV}^{3}(\%)$} \\
\hline & $100 \% \mathrm{FBC}$ & $33 \% \mathrm{MBC}$ & $66 \% \mathrm{MBC}$ & $100 \% \mathrm{MBC}$ & \\
\hline Comprimento $(\mathrm{cm})($ Length) & 7,21 & 7,02 & 7,03 & 7,15 & 3,46 \\
\hline Peso $(g)($ Weigh $)$ & 19,71 & 18,71 & 19,57 & 20,00 & 9,65 \\
\hline Diâmetro $(\mathrm{cm})$ (Diameter) & 1,40 & 1,40 & 1,35 & 1,42 & 6,91 \\
\hline Resistência $(\mathrm{N})^{2}$ & 946 & 930 & 940 & 935 & 1,45 \\
\hline \multicolumn{6}{|l|}{ Breaking strength } \\
\hline Gordura $(\%)(F a t)$ & 17,89 & 16,91 & 15,28 & 14,61 & 23,48 \\
\hline Cinza ASA $(\%)^{1}($ Ash $)$ & 52,43 & 51,07 & 50,02 & 49,47 & 5,31 \\
\hline Cinza ASE $(\%)^{1}(A s h)$ & 54,98 & 53,37 & 52,18 & 54,13 & 5,99 \\
\hline Fósforo (\%) ${ }^{1}$ (Phosphorus) & 11,77 & 11,43 & 11,32 & 11,03 & 6,02 \\
\hline Cálcio $(\%)^{1}$ (Calcium) & 19,60 & 18,53 & 18,53 & 17,94 & 5,70 \\
\hline Magnésio (\%) (Magnesium) & 2,85 & 2,81 & 2,62 & 2,77 & 8,89 \\
\hline Flúor (\%)(Fluorine) & 0,514 & 0,385 & 0,420 & 0,366 & 37,31 \\
\hline Espessura do periósteo $(\mu \mathrm{m})$ & 113,8 & 122,09 & 109,14 & 109,3 & 22,08 \\
\hline \multicolumn{6}{|l|}{ Periosteal thickness } \\
\hline Espessura da compacta $(\mu \mathrm{m})^{1}$ & 821,9 & 749,08 & 1326,97 & 1352,5 & 12,33 \\
\hline Compact layer & & & & & \\
\hline $\begin{array}{l}\text { Relação compacta/periósteo }{ }^{1} \\
\text { Compact/periosteal ratio }\end{array}$ & 7,22 & 6,14 & 12,16 & 12,36 & 28,46 \\
\hline
\end{tabular}

\footnotetext{
${ }^{1}$ Efeito linear $(\mathrm{P}<0,01)$ (Linear effect, $\left.P<.01\right)$.

2 Resistência do osso em $\mathrm{N}$, em que $1 \mathrm{~N}=0,1020 \mathrm{kgf} / \mathrm{mm}$ (Breaking strength of bone in $\mathrm{N}$, where $1 \mathrm{~N}=.1020 \mathrm{kgf} / \mathrm{mm}$ ).

3 Coeficiente de variação.

FBC: fosfato bicálcico (FBC: Dicalcium phosphate); MBC: Fosfato monobicálcico (MBC: Monodicalcium phosphate).
}

\section{R. Bras. Zootec., v.34, n.1, p.142-150, 2005}


fósforo das fontes de fósforo e cálcio, mas também a biodisponibilidade de cálcio.

A deficiência de cálcio e de fósforo pode resultar em prejuízo na mineralização dos ossos, redução do crescimento ósseo e crescimento deficiente. Suínos adultos consumindo dietas deficientes mobilizam cálcio e fósforo dos ossos, apresentando ossos frágeis (osteoporose). Isso pode resultar em uma condição denominada "porcas deitadas". Entretanto, não foram observados sinais de deficiência nos animais que consumiram MBC.

Apesar de não ter sido diferente estatisticamente, o teor de magnésio e de flúor nos ossos mostrou tendência de redução nos animais que consumiram níveis crescentes de $\mathrm{MBC}$, o que pode estar relacionado ao baixo teor de flúor e magnésio do MBCs. Entretanto, o flúor constitui um mineral importante, pois, no organismo, apresenta grande afinidade por tecidos duros mineralizados, onde substitui o composto hidroxiapatita por flurapatita

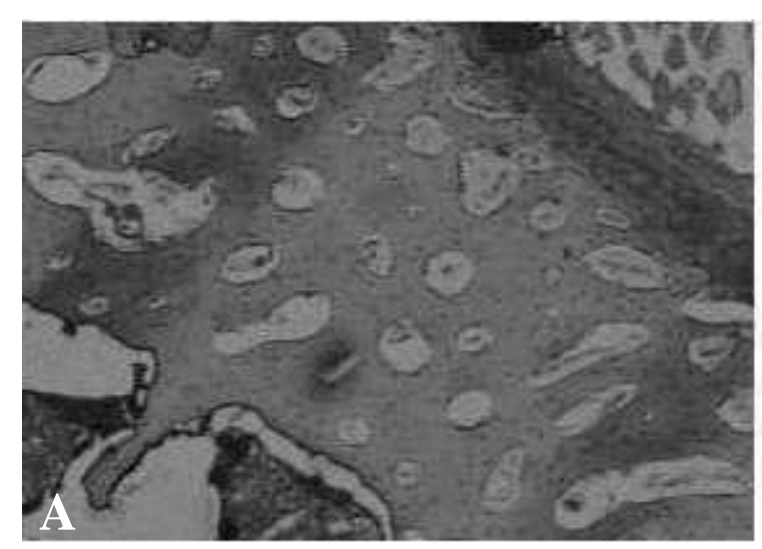

(Barbosa et al., 1993). Contudo, o excesso de flúor pode provocar incoordenação motora nos suínos (Bellaver et al., 1991). A sensibilidade à intoxicação por flúor obedece a uma escala decrescente: bovinos, caninos, eqüinos, ovinos, suínos e aves (Shupe \& Olson, 1983).

As alterações histológicas (Figura 1) observadas no osso cortical dos animais que receberam níveis crescentes de MBC podem ter sido acompanhadas por aumento da porosidade óssea, pois não foi constatado incremento na resistência óssea, mas sim diminuição dos teores de cálcio e de fósforo, o que sugere maior reabsorção óssea.

\section{Conclusões}

Em suínos nas fases de crescimento e terminação, a substituição total e/ou parcial do fosfato bicálcico pelo monobicálcico não influencia o desempenho dos animais.

Figura 1 - Secções de ossos da costela dos suínos aos $90 \mathrm{~kg}$ de peso. As letras A e B, nas fotomicrografias, correspondem respectivamente aos ossos de suínos alimentados com as dietas contendo 100\% FBC e 100\% MBC. Em B, detalhe da: (M) tecido muscular; (EP) periósteo; (T) osso esponjoso e (EC) camada compacta. Aumento: $40 \mathrm{X}$. Coloração: HE.

Figure 1 - Slices of the rib bones of the swine with $90 \mathrm{~kg}$ of weight. The letters $A$ and $B$, in the photo, correspond to the swine bones fed with diets contends $100 \%$ FBC and 100\% MBC. In B, detail of the: (M) muscular tissue; (EP) periosteal; (T) bony spongy and $(E C)$ layer compacts. Increase: 40 X. Coloration: HE.

\section{Literatura Citada}

AMMERMAN, C.B.; ARRINGTON, L.R.; McCALL, J.T. et al. Inorganic phosphorus utilization by swine as measured by an isotope technique. Journal of Animal Science, v.22, n.2, p.890-893, 1963.

ASSOCIAÇÃO NACIONAL PARA DIFUSÃO DE FONTES DE FÓSFORO NA ALIMENTAÇÃO - ANDIF. O fósforo na alimentação animal. São Paulo: 1997. 74p. (Séries Técnicas 1).

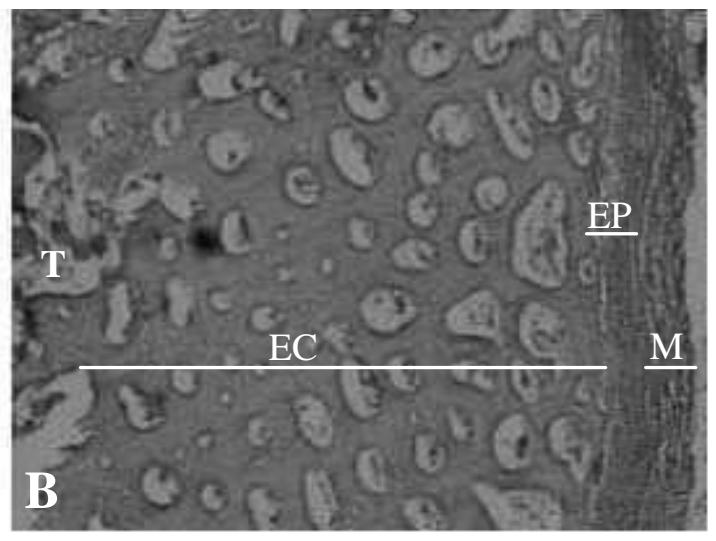

R. Bras. Zootec., v.34, n.1, p.142-150, 2005

BARBOSA, H.P.; FIALHO, E.T.; LIMA, G.J.M.M. Efeitos dos níveis de flúor proveniente de fosfato de Patos de Minas no desempenho e características do osso de suínos em crescimento e terminação Boletim da Indústria Animal, v.50, n.1, p.1-5, 1993.

BARBOSA, H.P.; MORES, N.; FIALHO, E.T. et al. Comparação de fontes de fósforo para suínos em diferentes idades. I. Aleitamento e creche. Boletim da Indústria Animal, v.52, n.2, p.119-125, 1995. 
BARBOSA, H.P.; MORES, N.; FIALHO, E.T. et al. Efeitos dos níveis de flúor provenientes dos fosfatos de Tapira e monocálcico no desempenho e características do osso de suínos em crescimento e terminação. Revista Brasileira de Zootecnia, v.21, n.5, p.838-846, 1992.

BELLAVER, C.; GOMES, P.C.; FIALHO, E.T. et al. Fosfatos de rocha em dietas para suínos formuladas com base no fósforo disponível. Pesquisa Agropecuária Brasileira, v.26, n.10, p.1771-1776, 1991.

BOYD, R.D.; HALL, D.; WU, J.F. Plasma alkaline phosphatase as a criterion for determining biological availability of phosphorus for swine. Journal of Animal Science, v.57, n.2, p.396-401, 1983.

CARDOSO, J.L.A. Produção, processamento e perspectiva do fosfato na alimentação animal. In: MINI SIMPÓSIO DO COLÉGIO BRASILEIRO DE NUTRIÇÃO ANIMAL, 1991, Campinas. Anais... Campinas: Colégio Brasileiro de Nutrição Animal, 1991. p.35-52.

CROMWELL, G.L. Requeriments, biological availability of calcium, phosphorus for swine evaluated. Feedstuffs, v.61, n.23, p.16-20, 1989.

DOIGE, C.E.; OWEN, B.D.; MILLS, J.H.L. Influence of calcium and phosphorus on growth and skeletal development of growing swine. Canadian Journal of Animal Science, v.55, n.1, p.147-164, 1975.

ENGSTRON, G.W.; HORST, R.L.; REINHARDT, T.A. et al. Effect of dietary phosphorus levels on porcine renal 25-hydroxyvitamin D, 1 a and 24-R hidroxylase activities and plasma 1,25-hydroxyvitamin $\mathrm{D}_{3}$ concentration. Journal of Animal Science, v.60, n.5, p.1005-1011, 1985.

FIGUEIRÊDO, A.V.; VITTI, D.M.S.S.; LOPES, J.B. et al. Disponibilidade biológica do fósforo de fontes fosfatadas determinada por intermédio da técnica de diluição isotópica. II. Suínos em crescimento. Revista Brasileira de Zootecnia, v.30, n.5, p.1514-1520, 2001.

FISHER, L.J. A comparison of supplemental forms of phosphorus. Canadian Journal of Animal Science, v.58, p.313-317, 1978.

GOMES, P.C. Exigência nutricional de fósforo e sua disponibilidade em alguns alimentos para suínos de diferentes idades. Viçosa, MG: Universidade Federal de Viçosa, 1988. 163p. Tese (Doutorado em Zootecnia) - Universidade Federal de Viçosa, 1988.

GUEGEN, L. La biodisponibilité du calcium des alinents. Cahiers de Nutrition et diététique, v.25, n.4, p.233-236, 1990.

IMAGE - PRO PLUS 1.3.2. The proven solution for image analysis. Reference Guide, 1994.

KOCH, M.E.; MAHAN, D.C. Biological characteristics for assessing low phosphorus intake in finishing swine. Journal of Animal Science, v.62, p.163-172, 1986.

LIMA, F.R.; MENDONÇA, C.X.; ALVAREZ, J.C. et al. Chemical and physical evaluations of commercial dicalcium phosphate as source of phosphorus in animal nutrition. Poultry Science, v.74, n.10, p.1659-1670, 1995.

LOPES, J.B. Avaliação da absorção real e das perdas endógenas de fósforo para suínos pela técnica de diluição isotópica. Piracicaba: Universidade de São Paulo, 1998, 87p. Tese (Doutorado) - Universidade de São Paulo, 1998.
LOPES, J.B.; VITTI, D.M.S.S.; FIGUEIRÊDO, A.V. et al. Avaliação das perdas endógenas e das exigências de fósforo, por meio da técnica da diluição isotópica, para suínos em crescimento. Revista Brasileira de Zootecnia, v.28, n.4, p.773-778, 1999.

MEDEIROS, S.L.S. Desempenho de suínos em terminação suplementados com quatro fontes de fósforo disponível. Belo Horizonte, MG: Universidade Federal de Minas Gerais, 1999. 54p. Dissertação (Mestrado em Zootecnia) - Universidade Federal de Minas Gerais, 1999.

MORES, N.; BARBOSA, H.P.; BARIONI Jr., W. Efeito de diferentes fontes de fósforo na dieta sobre as características dos ossos de porcas e suas proles. Pesquisa Veterinária Brasileira, v.19, n.1, p.1-6, 1999.

NUNES, R.V.; BUTERI, C.B.; NUNES, C.G.V. et al. Fatores antinutricionais dos ingredientes destinados à alimentação animal. In: SIMPÓSIO SOBRE INGREDIENTES NA ALIMENTAÇÃO ANIMAL. Anais... Campinas: Colégio Brasileiro de Nutrição Animal, 2001. p.235-272.

PEELER, H.T. Biological availability of nutrients in feeds: availability of major mineral ions. Journal of Animal Science, v.35, n.3, p.695-712, 1972.

PEELER, H.T. Biological availability of nutrients in feeds: availability of major mineral ions. Journal of Animal Science, v.35, n.3, p.695-712, 1972.

PENIDO, M.G.M.G.; LIMA, E.M.; MARINO, V.S.P. et al. Bone alteration in chidren with idiopathic hypercalciuria at the time of diagnosis. Pediatric Nephology, v.18, p.133-138, 2003.

ROSS, R.D.; CROMWELL, G.L.; STAHLY, T.S. Effects of source and the particle size on biological aviailability of calcium supplements for growing pigs. Journal of Animal Science, v.59, n.1, p.125-134, 1984.

ROSTAGNO, H.S.; ALBINO, L.F.T.; DONZELE, J.L. et al. Tabelas brasileira para aves e suínos: composição de alimentos e exigências nutricionais. In: REUNIÃO ANUAL DA SOCIEDADE BRASILEIRA DE ZOOTECNIA, 37., 2000, Viçosa, MG. Anais... Viçosa, MG: Sociedade Brasileira de Zootecnia, 2000. p.141.

STATISTICAL ANALYSES SYSTEM - SAS. SAS system for Windows. release 6.12. Cary: 1996. 01 CD-ROM.

SHUPE, J.L.; OLSON, A.E. Clinical and pathological aspects of fluoride toxicosis in animals. In: SHUPE, J.L.; PETERSON, H.B.; LEONE, N.C. (Eds.). Fluorides effects on vegetation, animals and humans. Utah: 1983. p.319-338.

SILVA, D.J. Análise de alimentos (métodos químicos e biológicos). Viçosa, MG: Universidade Federal de Minas Gerais, 1990. 165 p.

VELOSO, J.A.F. Perspectiva de uso dos fosfatos de rocha nacionais na alimentação animal. Belo Horizonte: Centro de Extensão da Escola de Veterinária da UFMG, 1991. p.55-84. (Caderno técnico 6)

VIANA, J.A.F. Fontes de sais minerais para bovinos e o desafio de suplementos de fósforo no Brasil. In: SIMPÓSIO SOBRE NUTRIÇÃO DE BOVINOS, 1985, Piracicaba. Anais... Piracicaba: Fundação de Estudos Agrários Luiz de Queiroz, 1985. p.47-66.

Recebido em: 06/05/03 Aceito em: $31 / 08 / 04$ 